\title{
Research on Maritime Silk Road-based Product Integration under Metaphorical Cognitive Framework
}

\author{
Xin Qinying \\ School of Culture Communication, Liming Vocational University, Quanzhou 362000, China
}

\begin{abstract}
The hierarchy-based metaphorical cognitive framework is constructed to integrate the product design with the Maritime Silk Road culture of southern Fujian via channels including cultural symbols, its utilization as well as connotations involved. Specifically, integration of various elements along with expanded functions and details could further reveal the charm of cultural designs. Such practices could serve a way to testify the efficiency of these designs in cultural communication, thus providing references for the teaching of cultural and creative product design as well as product designs by factories.
\end{abstract}

\section{Introduction}

The process of metaphor is to connect the noumenon and the metaphor based on their similarities, thus generating the image cognition of the other. Based on the metaphorical cognitive theory of product design, noumenon and metaphor are collections of certain features and concepts, or the "domain" [1]. In the design of cultural and creative products, a cognitive structure can be set up between the domains of noumenon and the metaphor, thus generating corresponding design elements to promote the resonance of cultural cognition, so as to present the cultural connotation of products.

\section{Metaphorical Cognitive Framework}

Metaphorical cognition depends on imagination and associations involved[2]. In the face of cultural and creative products, acceptance from the audience is directly linked to their imagination inspired by the cultural symbols concerned to understand the intentions of the design. There are three levels of metaphorical cognition based on people's understanding of cultural symbols, including form, indication and connotation, from which the structure of metaphorical cognition is established. The extrinsic values of cultural symbols reveal the beauty of form to the public who has a rough understanding of cultural symbols under the framework of metaphorical cognition. As to the indicative functions, cultural symbols reveal metaphors via experiences of the public, informing them of their utilization. In terms of connotation, the intrinsic values of cultural symbols are well accessed by people with a full knowledge in this regard. The three levels are arranged in a bottom-up manner. 


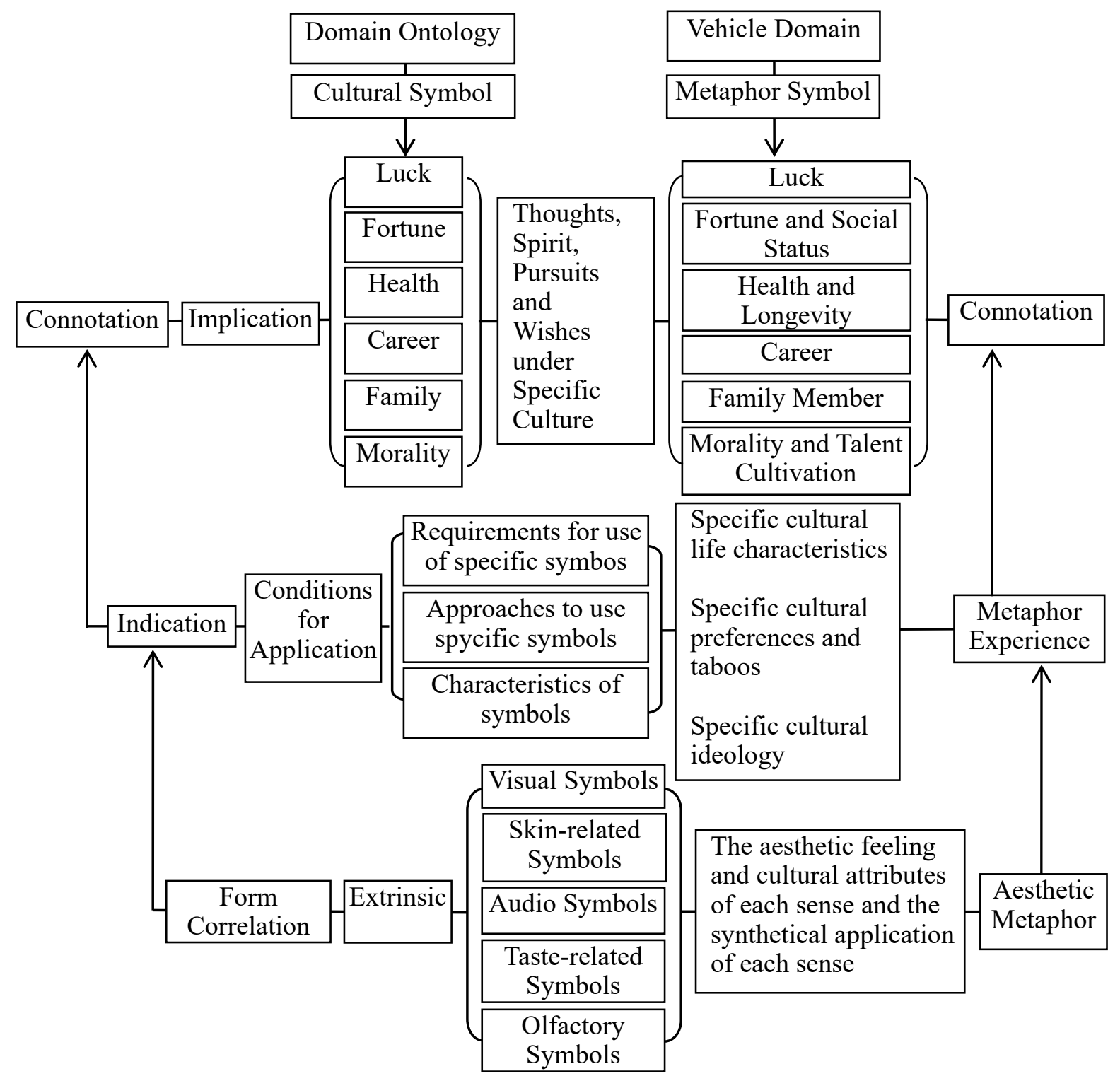

Figure 1 Metaphorical Cognitive Framework Targeting the Design of Cultural and Creative Products.

\section{Integration of Maritime Silk Road Culture and Product Design under the Metaphorical Cognitive Framework}

The ancient Quanzhou Port, located in southern Fujian, is the starting point of the ancient Maritime Silk Road. Trade prosperity promotes the coexistence of multi-cultural exchanges, which continues to this day. Maritime Silk Road culture is a coastal culture formed by the integration and evolution of multiple cultures [3]. Based on the metaphorical cognitive framework and the characteristics of the Maritime Silk Road culture, there are several ways to integrate the Maritime Silk Road culture with product design.

\subsection{Integration of cultural symbols and product design in terms of forms}

At the form level, cultural symbols related to various senses cannot be separated from the expression of patterns, colors and textures. Therefore, at this level, the integration of Maritime Silk Road cultural symbols and product design includes the following three aspects.

3.1.1 Incorporation Of Maritime Silk Road-based image patterns. The image pattern refers to the pattern with cultural orientation. The refinement and application of the image pattern of Maritime Silk Road culture should not only depend on aesthetic values, but should further explore the cultural meaning behind it, and determine how to incorporate the pattern into product design in an appropriate manner. For example, in the maritime culture, the fish-eye pattern of the ancient ships in southern Fujian expressed the hope of "distinguishing direction on the sea and staying safe from waves". By incorporating this pattern into the product, the metaphorical cognition of "everything goes well" is formed, thus further enhancing the cultural implication of the product.

3.1.2 Integration of Classic Maritime Silk Road-based colors. The classic colors of Maritime Silk Road can be integrated with the product design based on colors of 
cities along the road and their color collocation so as to find out the best color representing the culture for further utilization. For example, the traditional folk houses in southern Fujian were built upon red bricks in the wall, red tiles on the roof and red bricks on the indoor floor. Through aerial photography, cities in Fujian province sparkled in red, thus earning the reputation of "Southern Fujian Red". Different from "China Red", it is slightly golden in red, with a relative dull color, endowing it with visual impacts in the midst of green plants in the city. Such color application in the packaging design of cultural and creative products can form an obvious aesthetic metaphor of southern Fujian culture.
3.1.3 Integration of traditional textures of Maritime Silk Road culture. The texture of materials used in different traditional techniques of Maritime Silk Road culture enjoys unique beauty, with the mixture of various traditional materials serving as a supplement to each other, thus producing the metaphorical effect of traditional texture of Maritime Silk Road culture. For example, the work of Lianfa Tin Shop, a tea set titled "Prosperity Every Year" (Figure 1.2) [4], shows the beauty of the local texture and forms an aesthetic metaphor through the contrast of the tin carving and Dehua ceramics apart from indicating its intrinsic implications.

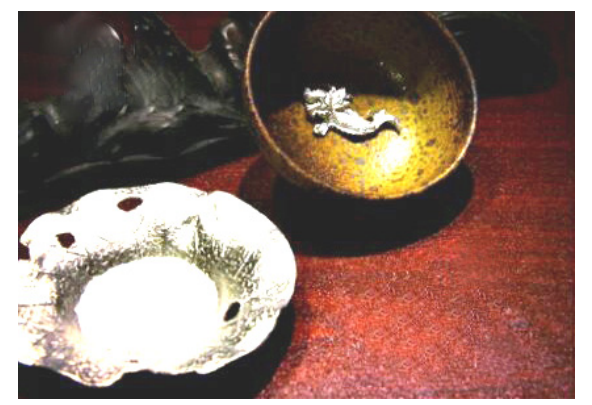

Figure 2 The Tea Set of "Prosperity Every Year" by Lianfa Tin Shop.

\subsection{Integration of symbols with product design at the indication level}

The cultural symbols of the Maritime Silk Road have specific requirements and channels for application, including occasions and taboos. Deviation and conflicts taking place in the design and application of cultural symbols would make it difficult be accepted by the audience at this metaphorical cognitive level. For example, the Qingjing Temple in Quanzhou is a typical Islamic architecture. However, if the product design ignores its religious taboos and randomly applies parts of its worship hall to the products, it is easy to arouse disputes despite the aesthetic values provided by the product.

\subsection{Integration of cultural intrinsic values and product design at the connotation level}

The cultural symbols with implications of Maritime Silk Road endow the products with introverted, implicit and unobtrusive values, allowing spiritual communication with the users. The use of such cultural symbols reflects metaphors embedded in the thoughts, spirits, pursuits and aspirations under the culture.

\subsubsection{Integration of thought and spirit. In southern} Fujian, the Taoist philosophy that "For I am abstracted from the world, the world from nature, nature from the way, and the way from what is beneath abstraction" is closer to the realistic and pragmatic life of local residents. The essence of Taoist thoughts is reflected in the harmonious coexistence between man and nature, which promotes self-cultivation and the integration of body and mind. The philosophy is manifested in the following aspects of the design: Respect local conditions and the natural environment in the pursuit of the stunning beauty of artifacts [5]. For example, the plain nature of traditional furniture in southern Fujian, the proper mortise and tenon joint structure, the coordination of the back of the chair and the radian of the human body, are the embodiment of Taoism with ideological connotation metaphor.

3.3.2 Integration of blessings with the design. The blessings of Maritime Silk Road culture are expressed by various symbols, which could be integrated into the design of products to deliver such implications. For example, the images of persimmon and peanut could be applied to the product to embody luck (because the pronunciation of the two plants sounds like "good things are going to happen" in Chinese). Teapot made of tin carving means "cherish"(because tin carving sounds like "cherish one's blessings" in Chinese). The statue of a red-crowned crane standing on a turtle and singing implies brilliant feat and championship.

3.3.3 Integration of nostalgia into the design. By optimizing the existing recognized elements of Maritime Silk Road and applying the contents, symbols and symbolic elements of traditional stories or life into the design could bring about more conceptual values, enabling the products to serve as an effective carrier of culture.

For example, in southern Fujian and Taiwan, the washboard, a traditional tool used for washing clothes, is widely used by the elderly, with their grandchildren standing by along the riverside or in the courtyard. The relish plate in the picture (Figure 2.1), called "Grandma's Washboard", is inspired by the washboard. The image of 
washboard expresses nostalgia and implies the love from

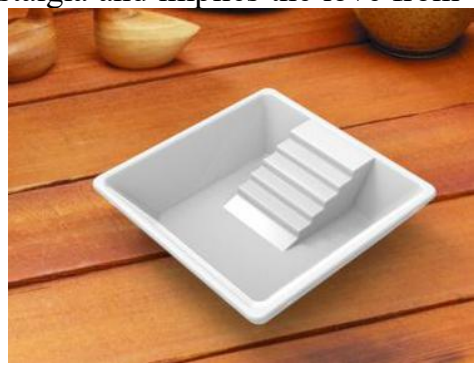

Figure 3 Relish Plate -“Grandma's Washboard”.

\section{Integration of Maritime Silk Road culture based on metaphorical cognitive framework}

\subsection{Integration of cultural elements of Maritime Silk Road in terms of form}

In the traditional architectural cultural symbols of the Maritime Silk Road, the top of the "swallow-tail ridge" is protruding towards the sky, implying that this household has a Ju-ren (a successful candidate in the imperial examinations at the provincial level in the Ming and Qing dynasties)[6]. Therefore, "swallow-tail ridge" in southern Fujian also flaunt family glory. The semantics of "swallow-tail ridge" can be extracted and refined with corresponding color collocation.

The multi-functional desk lamp shown in Figure 2.1

grandma and hometown.

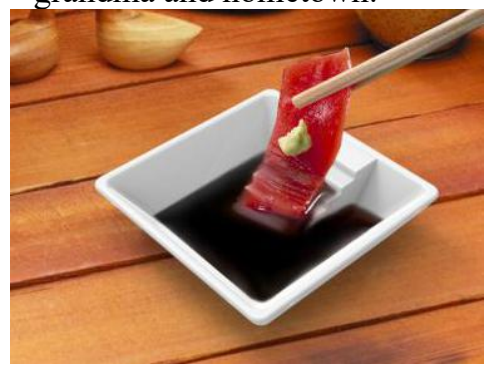

below is a new product that combines the functions of desk lamp and screen-less TV bracket. The inspiration comes from the swallow-tail ridge of traditional architecture in southern Fujian. The desk lamp support, which can be expanded up and down, can help hold or support the lamp with the upward swallow-tail ridge, making it easier to pull the lamp. This product has been awarded the First Prize of "Challenge Cup - Rainbow Life" National Vocational School Innovation and Entrepreneurship Competition in 2016, and has applied for relevant patent.
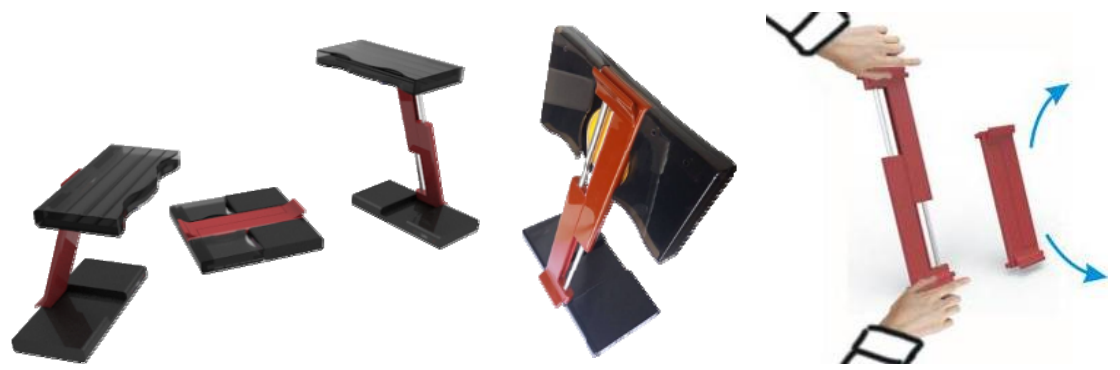

Figure 4 Gui Multi-functional Desk Lamp.

\subsection{Integration of Maritime Silk Road functions into the design at the implication level}

The drum lock design in Figure 2.2 is inspired by the shape of Chinese drum, with the Chinese red as the main color in collocation. In terms of functional symbols, the common traditional carvings in southern Fujian is extracted for graphic elements in the design(that coincide with the Chinese style drum lock). Then, the pattern is made into a reflective film and covered on the drum lock. When driving, the lock could be placed on or after the handlebars frame, serving as a reflector lamp. Moreover, the application of cultural symbols will not conflict with cultural taboos. The product won the Silver Award of the First Fujian University Students' Innovation and Creative Design Competition in 2017 and has applied for a patent. 


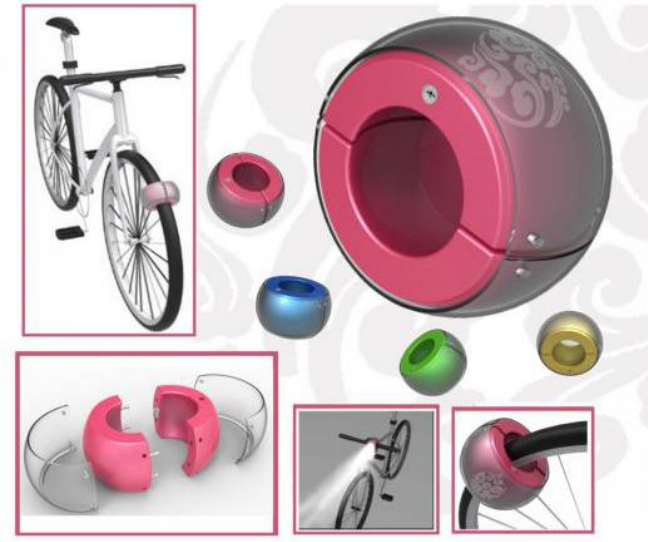

Figure 5 Reflective Film of the Drum Lock.

eyes", expressing blessings to sailors and wishing them all the best. This design, inspired by the "Boat of

\subsection{Integration of Maritime Silk Road culture at the connotation level}

The "Boat of Happiness" is flat bottom in shape, with a broad body and both tails pointing up-toward. It is a treasure of shipbuilding in Chinese history and the symbol of the Maritime Silk Road [7]. The side of the bow is decorated with fish eyes, also called "the dragon's Happiness", introduced the fish-eye pattern to the switch on one side of the keyboard while decorating the other side with a fish eye as well. The design won the Silver Award in the Second Fujian Province "Challenge Cup Rainbow Life" Innovation and Entrepreneurship Design Competition in 2018, and has applied for a patent.

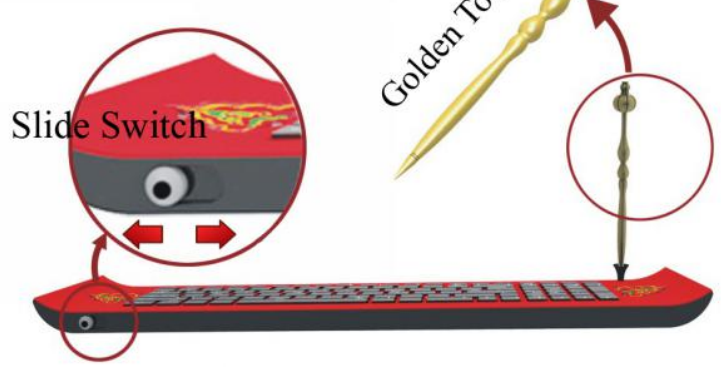

Figure 6 The Reflective Film of Drum Lock.

\section{Conclusion}

The metaphorical cognitive structure is constructed hierarchically based on the understanding of the culture among the audience, with distinctive features for design at each level. Based on this, the integration of Maritime Silk Road with the product design can be achieved through cultural symbols and the application of cultural implications. Through attempts of different design strategies to carry on the heritage of the Maritime Silk Road culture, the integration of culture and product design will be further explored. However, the approaches and strategies are not independent in use, but coordinated under overall consideration, thus guaranteeing the efficiency.

\section{Acknowledgment}

Funded by Liming Vocational University for the university-level project: Study of Product Pattern Design APP software (LZ2019)

\section{References}

1. Li, N., Su, K., Chu, J.J. (2017) Theory Method of Product Design in the View of Multimodal Metaphor. Packaging Engineering, 38: 157-160.

2. Zhu, Y. (2016) Metaphor and Construction of Product Artistic Conception. Journal of Hefei University of Technology(Social Science), 30: 105-107.

3. Guo, L.N., Li, W.S., Song, D. (2018) A Research on the Influence of the Maritime Silk Road Culture on the Traditional House in Quanzhou. Journal of Quanzhou Normal University, 36: 94-98.

4. Lianfa Tin Shop. (2018) The Creativity of Lianfa Tin Shop. https://www.meipian.cn/5hbowfc.

5. Zhang, C.H. (2014) Research on Application of Taoist Thought in Home Design. Journal of East China Jiaotong University, 31: 156-157. 
6. National Architecture Institute of China. (2017) Swallow Tail Ridge--Roof Shaping of Ancient Buildings.

http://www.naic.org.cn/html/2017/gjwg_1018/2 8626.html.

7. Gao, Y. (2011) The Development and Historical Influence of Fu-boat. Journal of Minxi Vocational and Technical College, 13: 47-50. 